\title{
An In Vitro Demonstration of Increased Collecting Tubular Permeability to Urea in the Presence of Vasopressin *
}

\author{
Kenneth D. Gardner, Jr., $\dagger$ and Roy H. Maffly $\ddagger$ \\ (From the Department of Medicine, Stanford University School of Medicine, Palo Alto, Calif.)
}

In the mammalian kidney the final step in the formation of a concentrated urine now is recognized to be the net extraction of water from collecting tubular fluid (1-3). Available evidence indicates that sodium and urea, in addition to water, leave this segment of the nephron (3-5). The forces that drive these molecules presumably are those which drive molecules across other biological membranes. They may include the chemical, electrical, and hydrostatic pressure gradients across the collecting tubular wall and active transport mechanisms in the wall. The rate at which these molecules move is governed also by the permeability characteristics of the wall.

In the intact kidney it is difficult to assess with confidence the degree to which each of these factors affects molecular movement and consequently the final concentration of the urine. Transmural gradients in vivo may change with alteration in the medullary patterns of countercurrent flow, whereas active transport mechanisms and permeability characteristics may vary in response to hormones (6). In order to control these variables, an in vitro technique has been devised for the perfusion of collecting tubules in the isolated medullary pyramid of the rodent kidney. With this technique collecting tubular permeability can be characterized in an experimental environment

* Submitted for publication January 6, 1964 ; accepted June 24, 1964.

Portions of this work were presented to the Western Section Meeting and to the General Session of the National Meeting of the American Federation for Clinical Research in Carmel, Calif., on January 28, 1963 (Clin. Res. 1963, 11, 91), and in Atlantic City, N. J., on April 28, 1963 (Clin. Res. 1963, 11, 241), respectively. The investigation was supported by research grant no. AM 06593-01 from the Council on Arthritis and Metabolic Diseases of the U. S. Public Health Service and by grant no. IN32-C from the American Cancer Society.

$\dagger$ Daland Fellow of the American Philosophical Society. $\$$ Established Investigator of the American Heart Association. in which countercurrent forces no longer influence the movement of molecules across the collecting tubular wall. Using it, we have examined the permeability of the rat collecting tubule to urea.

Among the solutes of collecting tubular fluid, urea is one of the most prevalent (7). During antidiuresis, as water leaves the tubule, the intraluminal concentration of urea rises. This rise would limit further water reabsorption were not the collecting tubular wall permeable to urea (3, 5, 8). Berliner, Levinsky, Davidson, and Eden have pointed out that the trapping of urea by medullary countercurrent flows would allow the rising intraluminal concentration of urea to be balanced by an equally high interstitial concentration of urea (2). Under such conditions urea would have no net osmotic effect across the wall and therefore would not retard water reabsorption from the tubule.

In 1959 Crawford, Doyle, and Probst presented evidence that urea actually enhances water reabsorption in the rat kidney (9). They found that the administration of urea to rats resulted in a reduction of the animals' renal water requirement for the excretion of a given amount of nonurea solute, an observation similar to that recorded earlier by Gamble, McKhann, Butler, and Tuthill (10). This effect of urea was maximal when the ratio of urea to nonurea solute in the urine was 0.35 . The mechanism for this action of urea has not been established nor has its prevalence among mammals been ascertained. The present study, utilizing in vitro collecting tubular perfusion, was undertaken to define more precisely the role of urea in the urinary concentrating mechanism.

\section{Methods}

Observations have been made on 360 medullary pyramids taken from 180 male Wistar and Sprague-Dawley rats weighing 250 to $400 \mathrm{~g}$. All rats were maintained 


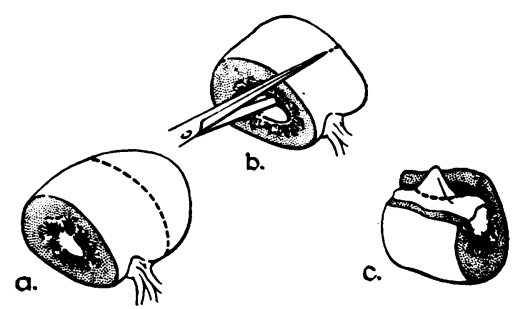

Fig. 1. Isolation of the medullary pyramid. Parallel cuts are made above and below the renal hilum (a). The point of the scissors next is inserted through the ureteral pelvic cavity, and cuts are made to expose the medullary pyramid (b). A final cut across the base of the papilla (c) allows it to be removed intact.

for at least 48 hours before sacrifice on tap water and Purina chow pellets ad lib. Rats with unilateral or bilateral hydronephrosis, found at sacrifice, were excluded from this study (11). With the exceptions to be mentioned, the protocol used in these studies was as follows: Under light ether anesthesia each animal was given 5 $\mathrm{ml}$ per $100 \mathrm{~g}$ body weight of tap water through a gastric tube and then was allowed to awaken. Forty-five minutes later the rat again was lightly anesthetized, reintubated, and given an identical volume of $12 \%$ ethanol to establish permanent anesthesia and to inhibit endogenous vasopressin release (12). Thirty minutes later the animal usually was asleep and urinating briskly. Through a ventral mid-line incision the kidneys and urinary bladder were exposed. A sample of urine was obtained by needle puncture of the bladder and was set aside for determination of osmolality by the freezing point depression technique. One renal pedicle was clamped, and the kidney was removed. (In alternate animals alternate kidneys were removed first for purpose of control.) An intravenous injection then was given which, in experi-
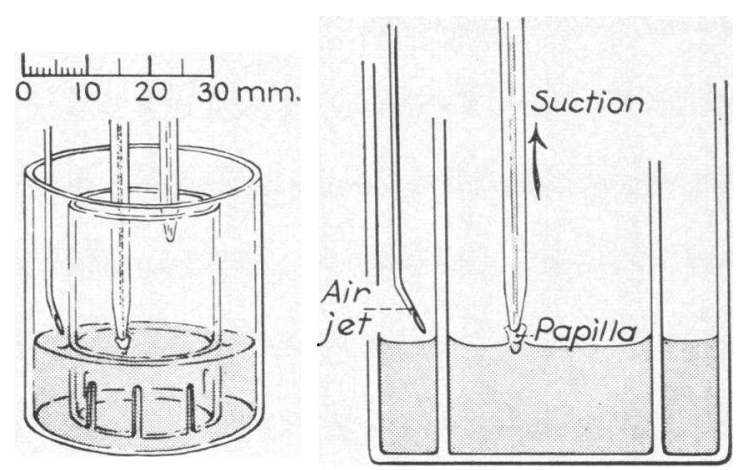

Fig. 2. Medullary pyramid Undergoing perfusion. Special chambers are used that allow circulation and oxygenation of the perfusate with $95 \%$ oxygen-5\% carbon dioxide through an "air-jet" while protecting the papilla from air and fluid turbulence. Each chamber accommodates two papillae. Note that only the tip of the papilla is immersed in the perfusate. The base of each chamber rests in a constant temperature bath at $37^{\circ} \mathrm{C}$. mental rats, consisted of $10 \mathrm{mU}$ of vasopressin (Pitressin) per $100 \mathrm{~g}$ body weight in $0.5 \mathrm{ml}$ physiological saline; control animals received saline without vasopressin. Five minutes after the injection, the second kidney was removed.

From each kidney the medullary pyramid was isolated as diagrammed in Figure 1. The pyramid was blotted and its weight recorded. Perfusion of the collecting tubules in each pyramid was accomplished by placing the cut surface of the tissue against the occluded end of a sintered glass filter stick (made from glass tubing of 1 $\mathrm{mm}$ internal diameter and plugged at one end by coarse grade sintered glass). A negative pressure of $52 \mathrm{~cm}$ of water was applied through the filter stick to the cut surface of the tissue in order to hold the tissue in position and to enhance collecting tubular perfusion. The tip of each pyramid then was immersed in Krebs saline solution

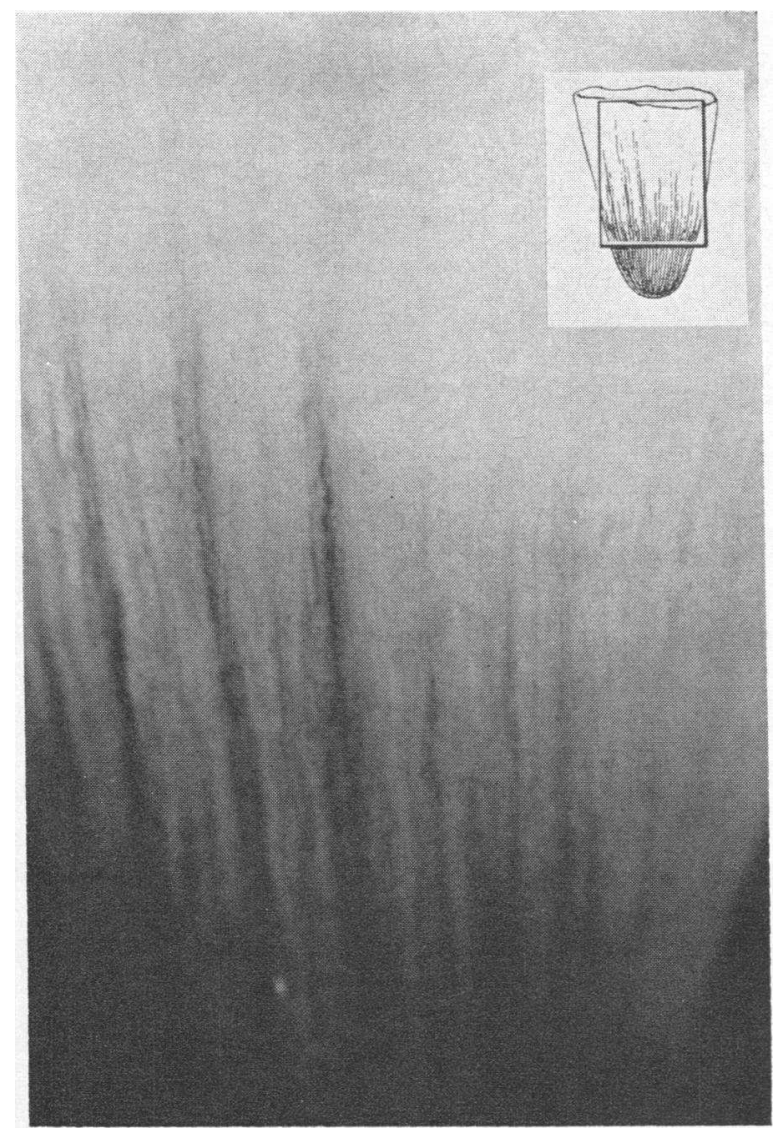

Fig. 3. Dye-perfusate in collecting tubules. A papilla is shown as it appears under the dissecting microscope after 15 minutes of perfusion with dye to demonstrate the filling of linear tubules that has occurred. The insert relates the area of the photograph to the entire papilla. The lower margin of the picture approximates the depth to which the papillary tip was immersed during perfusion. (From a colored photograph using a red filter. $\times 60$ ) 
(13). A papilla in position and undergoing perfusion is illustrated in Figure 2.

Visual confirmation of the selective collecting tubular filling that can be achieved in this manner was obtained by adding Evans blue dye to the perfusate in early trials with the technique. The appearance of one such papilla under the dissecting microscope after perfusion is shown in Figure 3. The linear collecting tubules, which are filled with colored perfusate, can be seen readily. No looping structures were ever found to contain the dyed perfusate.

In the present experiments tracer amounts of either sucrose $\mathrm{C}^{14}$ or urea $\mathrm{C}^{14}$ were added to the perfusate in place of dye. After perfusion, each papilla was withdrawn from the perfusate, rinsed with nonradioactive Krebs solution, blotted, reweighed, and dried overnight to constant weight. Homogenization of the tissue in $10 \%$ trichloroacetic acid and centrifugation of this homogenate yielded a clear supernatant fluid which contained the isotope that had accumulated in the papilla. In addition to this specimen, samples of fluid for isotope content determinations were obtained from the perfusing medium, which was sampled at equidistant intervals in time before and after each perfusion period. (Samples of perfusate were not taken during the period of perfusion in order to avoid contamination of either the tissue or its filter stick.)

Before counting, each sample was diluted with a solution of appropriate solute content so that all specimens had identical compositions except. for their isotope content. Samples of these solutions were planchetted onto lens paper, dried, and counted in a gas flow counter ${ }^{1}$ for a minimum of 2,000 counts per sample.

In the original study 160 papillae from 80 rats were perfused for 30 minutes with a solution of $280 \mathrm{mOsm}$

${ }^{1}$ Nuclear-Chicago model D 47 with a Mylar window. Nuclear-Chicago Corp., Des Plaines, Ill. per $\mathrm{kg}$ water. In a second study 160 papillae from 80 rats were divided into groups of ten and perfused for $15,30,45$, or 60 minutes, again using a perfusate of 280 mOsm per $\mathrm{kg}$ water. In a third study 40 papillae from 20 rats were perfused for 30 minutes with a solution whose osmolality had been raised from $280 \mathrm{mOsm}$ per $\mathrm{kg}$ water to 860 per $\mathrm{kg}$ water by the addition of sodium chloride.

\section{Results}

The 160 papillae of the original study were divided into four groups of 20 pairs each, based on the isotope used (sucrose $\mathrm{C}^{14}$ or urea $\mathrm{C}^{14}$ ) and on the injection given (saline alone or saline with vasopressin). Within each group every postinjection papilla was compared to its preinjection control, which had been taken from the same rat 5 to 10 minutes earlier and which was perfused almost concomitantly. The results of these comparisons were expressed as per cent change and were computed for papillary water content, papillary isotope content, and papillary dry weight. For each of the four groups of 20 pairs the means of these parameters were calculated and are presented, plus and minus their standard errors, in Figure 4.

Papillary water content (Figure 4a). The 40 papillae that were exposed in vivo to vasopressin contained an average of $24 \%$ more water than did their paired preinjection controls after perfusion $(\mathrm{p}<0.01$, with $31 \%$ more water in the series with urea $\mathrm{C}^{14}$ and $17 \%$ more water in the series with sucrose $\mathrm{C}^{14}$ ). No difference in papillary wa-

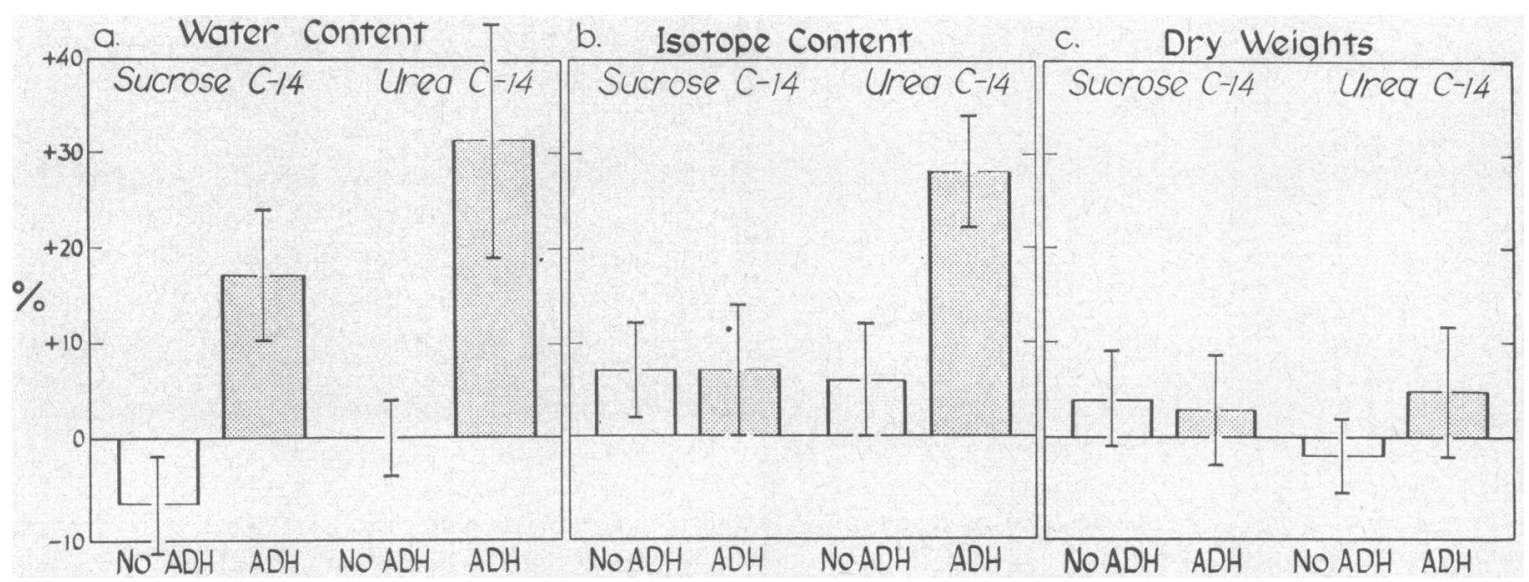

Fig. 4. Per cent difference in papillary water content, isotope content, and dry weight. Each bar represents the mean per cent difference ( $\pm 1 \mathrm{SE}$ ) among 20 pairs of pre- and postinjection papillae. The isotope used is indicated above the bar. The type of injection given is indicated beneath the bar with saline alone indicated by "No ADH" (antidiuretic hormone) and saline with vasopressin indicated by "ADH." 
ter content was found in papillae exposed to saline without vasopressin.

Papillary isotope content (Figure 4b). Exposure to vasopressin and to saline was not associated with an increase in the papillary content of sucrose $\mathrm{C}^{14}$. In contrast vasopressin-exposed papillae that were perfused with urea $\mathrm{C}^{14}$ contained $28 \%$ more radioactivity than did their paired preinjection controls $(\mathrm{p}<0.01)$. Greater urea $\mathrm{C}^{14}$ activity after vasopressin was found in 19 of the 20 pairs of papillae in this group. Saline-exposed papillae contained $6 \%$ more urea $\mathrm{C}^{14}$ activity, an increase not significantly different from zero. The difference between the vasopressin-exposed and the saline-exposed papillae (22\%) was significant $(\mathrm{p}<0.05)$.

Papillary dry weight (Figure 4c). There were no significant differences in the dry weights of the papillae among any of the four groups that were studied.

Variation of the perfusion period. The pertinent data from these studies are presented and analyzed in detail in the discussion to follow.

Isotonic versus hypertonic perfusate. Twenty pairs of papillae were studied with a perfusate of $860 \mathrm{mOsm}$ per $\mathrm{kg}$ water to which tracer amounts of urea $\mathrm{C}^{14}$ were added. When papillary water and isotope contents were analyzed in this group of papillae, no significant differences were found between the pre- and postinjection members of the 20 pairs. Urea $\mathrm{C}^{14}$ content was higher in

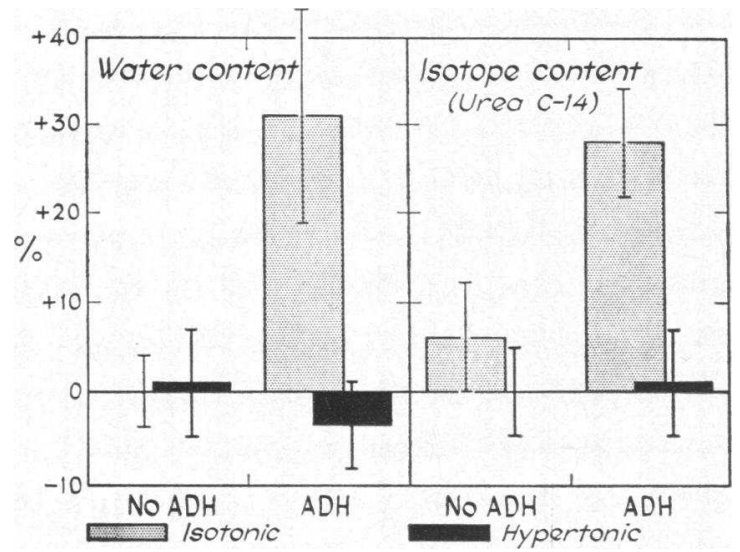

Fig. 5. Isotonic versus hypertonic perfusate. The previously recorded increases in papillary water and urea $\mathrm{C}^{14}$ contents are indicated by the stippled bars, whereas the same parameters measured after perfusion with a hypertonic solution are indicated by the black bars. nine and lower in 11 postinjection papillae. Water content was not significantly greater in vasopressin-exposed papillae. These results are contrasted with those from the experiments with isotonic perfusate in Figure 5.

\section{Discussion}

Papillae that were exposed in vivo to vasopressin with saline contained more water and more urea $\mathrm{C}^{14}$ after perfusion in vitro than did their paired preinjection controls in the initial study. The observation that injections of saline without vasopressin did not produce similar changes indicated that the observed differences in papillary water and urea $\mathrm{C}^{14}$ contents were attributable to an effect of vasopressin and not to some unrecognized variable in the experimental technique.

Effect of vasopressin on urea movement out of the collecting tubule. Several alternative explanations were considered to account for a greater content of urea $\mathrm{C}^{14}$ in the vasopressin-exposed papillae of the initial study : 1) increased collecting tubule volume, 2) expansion of the water space outside the collecting tubular lumen, 3 ) increased binding of urea in the medullary interstitium, and 4) enhanced movement of urea molecules through the collecting tubular wall.

Ginetzinsky (14) and Stolarczyk and Manitius (15) have described shrunken collecting tubular cells and dilated collecting tubular lumina in the antidiuretic rat. To assess the extent to which dilatation of collecting tubules might have contributed to a greater papillary content of urea $\mathrm{C}^{14}$, the intraluminal water space was estimated with sucrose $\mathrm{C}^{14}$, a molecule to which the collecting tubular wall is relatively impermeable (16). In contrast to urea $\mathrm{C}^{14}$, the papillary content of sucrose $\mathrm{C}^{14}$ was not altered by exposure to vasopressin. From this observation it was concluded that collecting tubular dilatation was not responsible for the increased papillary content of urea after vasopressin.

The second possibility was that vasopressin, by increasing the volume of extraluminal water, provided a larger compartment into which urea could pass, thereby increasing the volume of distribution of urea. From the data it seemed likely that papillary water had increased in a region of the papilla 
into which sucrose $\mathrm{C}^{\mathbf{1 4}}$ could not pass, since papillary water content was higher after vasopressin while the sucrose $\mathrm{C}^{14}$ content was unchanged. It was assumed that this region lay beyond the collecting tubule lumen, and it was designated the "nonsucrose" space. Presumably it contains cells, capillaries, lymphatics, and the interstitium. If, after 30 minutes of perfusion, urea $\mathrm{C}^{14}$ were to reach equilibrium in the water of this space whether or not vasopressin were present, any increase in the water content of this space would provide a larger volume into which urea $\mathrm{C}^{14}$ could pass. We reasoned that if this were the cause for increased papillary content of urea $\mathrm{C}^{14}$ after vasopressin, the concentration of urea in the water of the nonsucrose space $a$ ) should not rise further with perfusion periods of longer than 30 minutes and $b$ ) should be no greater in the vasopressinexposed than in the saline-exposed papillae.

To evaluate $a$ ), 16 groups of ten papillae were studied after $15,30,45$, or 60 minutes of perfusion as indicated above. These papillae were taken from rats prepared in the usual fashion and nephrectomized 5 minutes after injection with either saline or saline with vasopressin. Perfusion was carried out with either sucrose $\mathrm{C}^{14}$ or urea $\mathrm{C}^{14}$. The data obtained from these studies were prepared for analysis by randomly pairing a ureaperfused papilla with a sucrose-perfused papilla from the same time group and calculating a concentration of urea $\mathrm{C}^{\mathbf{1 4}}$ in the nonsucrose water in the following manner: 1) Isotope space $=$ per cent papillary water containing isotope: [ (counts per minute of isotope in papilla)/(counts per minute of isotope per microliter perfusate)]/[microliters of water in papilla after perfusion] $\times 100$; 2) nonsucrose urea $=$ per cent papillary water containing urea but not sucrose: isotope space for urea - isotope space for sucrose; 3 ) nonsucrose water $=$ per cent papillary water not containing sucrose: $100 \%$ - isotope space for sucrose; 4) concentration of urea in nonsucrose water (as per cent) : 2) $\div 3$ ) $\times 100$. The results of these calculations are given in Table $I$ and are plotted in Figure 6. In both groups of papillae the concentration of urea $\mathrm{C}^{14}$ continued to rise significantly after 30 minutes of perfusion, indicating that equilibration of urea in the nonsucrose water had not been achieved.

To evaluate $b$ ), the concentration of urea $C^{14}$
TABLE I

Concentration of urea in the nonsucrose water

\begin{tabular}{|c|c|c|c|c|}
\hline \multirow[b]{2}{*}{ Group } & \multirow{2}{*}{$\begin{array}{l}\text { Per- } \\
\text { fusion } \\
\text { time }\end{array}$} & \multirow[b]{2}{*}{ No. } & \multicolumn{2}{|c|}{$\frac{\text { Nonsucrose urea }}{\text { Nonsucrose water }} \times 100$} \\
\hline & & & $\begin{array}{c}\text { After } \\
\text { saline* }\end{array}$ & $\begin{array}{c}\text { After } \\
\text { vasopressin* }\end{array}$ \\
\hline & $\min$ & & & \\
\hline I & 30 & 20 & $31.3 \pm 4.8$ & $37.8 \pm 2.4$ \\
\hline \multirow[t]{2}{*}{ II } & $\begin{array}{l}15 \\
30 \\
45 \\
60\end{array}$ & $\begin{array}{l}10 \\
10 \\
10 \\
10\end{array}$ & $\begin{array}{l}33.7 \pm 4.7 \\
39.8 \pm 4.8 \\
43.0 \pm 8.3 \\
51.7 \pm 7.4\end{array}$ & $\begin{array}{l}34.3 \pm 2.1 \\
46.5 \pm 6.6 \\
57.3 \pm 6.7 \\
71.6 \pm 8.4\end{array}$ \\
\hline & Ove & $\begin{array}{r}\text { all mean } \\
\text { p }\end{array}$ & $38.5 \pm 2.6$ & $47.6 \pm 2.9$ \\
\hline
\end{tabular}

* Each value represents the mean \pm standard error of the number of determinations. The method of calculation of the concentration of urea in the nonsucrose water is given in the text.

in the nonsucrose water was calculated by using the data obtained in the initial series of experiments (group I, Table I). The concentration was higher in the vasopressin-exposed papillae, but the difference failed to achieve an acceptable statistical level $(p=0.20)$. A similar calculation based on the slopes of the vasopressin-exposed versus the saline-exposed papillae in the time experiments (group II, Table I and Figure 6) also failed to show statistical significance ( $p=$ 0.09 ). However, when the data from both series of experiments (groups I and II) were totaled, the concentration of urea $\mathrm{C}^{14}$ in the nonsucrose water of the vasopressin-exposed papillae averaged $47.6 \pm 2.9 \%$, whereas in the saline-exposed papillae it averaged $38.5 \pm 2.6 \%$. This difference was significant $(p<0.05)$, and it indicated that, in the nonsucrose space of those papillae which had been exposed to vasopressin, the content of urea had increased relatively more than had the content of water. From these observations it was concluded that expansion of the extraluminal water space could not explain the observed effect of vasopressin on the papillary content of urea $\mathrm{C}^{14}$ that was recorded in the initial study.

The third possibility that was considered was that vasopressin had either activated or increased interstitial binding of urea. This possibility was not excluded in the present study. In another vasopressin-sensitive tissue, the urinary bladder of the toad, a vasopressin-responsive binder for urea has been sought but has not been found (17). 


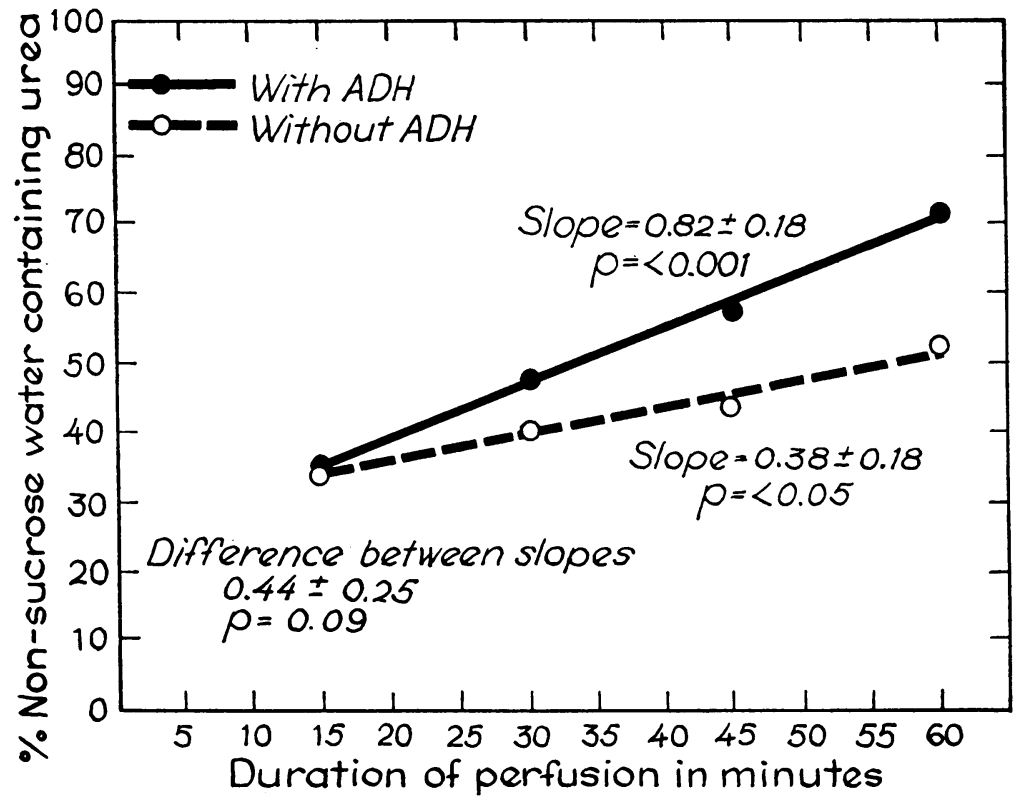

Fig. 6. EFFECT OF VASOPRESSIN AND TIME ON THE CONCENTRATION OF UREA IN THE NONSUCROSE WATER. The method for calculation of concentration of urea in the nonsucrose water is given in the text. The slopes have been calculated by the method of least squares. The figures indicate the slope of each line and the difference between the two slopes ( $\pm 1 \mathrm{SE})$.

Finally, the possibility was considered that vasopressin enhanced the rate of movement of urea molecules through the collecting tubular wall. Such enhancement might result from an increased permeability of the wall to urea, or from an increased driving force for urea movement across the wall in the form of either active transport or solvent drag. An attempt was made to divorce the movement of urea $\mathrm{C}^{14}$ from the movement of water out of the collecting tubular lumen by the substitution of a hypertonic perfusate for the isotonic one used in the initial study. When this was done, exposure to vasopressin no longer produced an increase in the papillary content of either water or urea $\mathrm{C}^{14}$. This observation, together with the fact that both water and urea $\mathrm{C}^{\mathbf{1 4}}$ increased in the nonsucrose space after vasopressin, suggested that solvent drag may have acted as a driving force for urea movement. Although a contribution by active transport to urea movement cannot be rigorously excluded, there is no need to invoke such an explanation to account for the results presented here. The acceptance of solvent drag as one factor that contributed to the movement of urea $\mathrm{C}^{14}$ does not exclude increased collecting tubular permeability to urea as a second contributing factor. On the contrary, if vasopressin enlarges "pores" in the collecting tubular wall, through which water and urea can flow, the "pores" must become sufficiently large to admit the urea molecule. An increased area for the diffusion of urea would result. Such a relationship between solvent drag and permeability to urea has been shown in the urinary bladder of the toad by Leaf and Hays (18).

Effect of urea on the urinary concentrating mechanism. In their report on the ability of urea to enhance water reabsorption in the rat kidney, Crawford and co-workers (9) considered three mechanisms by which urea might act: 1) through an effect on the self-diffusion of water, 2) through anomalous osmosis, and 3) through the active transport of urea by tubular cells. The first two mechanisms, although ingenious, are conjectural. The question of active urea transport by tubular cells in the mammalian kidney has not been answered satisfactorily to date (19-21). Whether urea enhances water reabsorption in the kidneys of other mammals as it does in the rat also remains in doubt. Drescher, Barnett, and 
Troupkou have pointed out that the data commonly cited from canine and human studies are as yet inadequate to rule out the possibility (22).

The results of the present study led us to seek a mechanism by which urea, moving passively across the collecting tubular wall in the presence of vasopressin, might enhance water reabsorption from collecting tubular fluid, at least in the rat. We assumed that water reabsorption from the collecting tubule takes place along an osmotic gradient that has been established across the tubular wall by the active transport of sodium into the medullary interstitium, primarily by the cells of the ascending limb of Henle's loop (23). It seemed reasonable that urea, when present in optimal amounts, might increase this driving force for water reabsorption.

The micropuncture data of Wirz (24), Lassiter, Gottschalk, and Mylle (25), and Ullrich and associates (23) have indicated the probability of an intramedullary cycle for urea in the antidiuretic rodent kidney. Our interpretation of this cycle is shown in Figure 7. During antidiuresis water reabsorption from the lower nephron increases

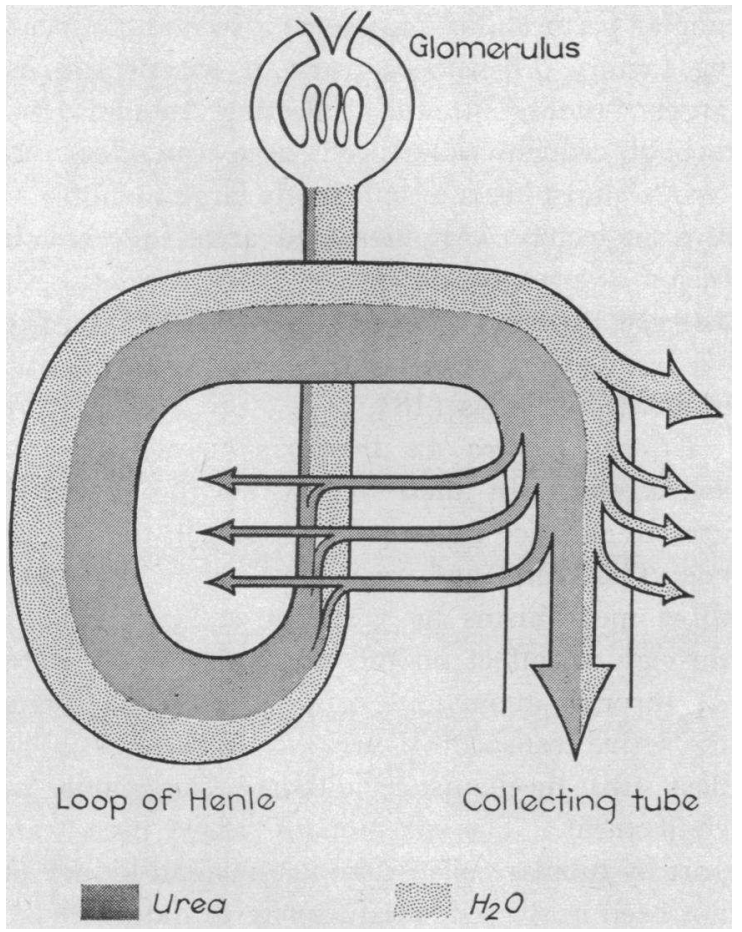

Fig. 7. INTRAMEDULLARY CYCLE FOR UREA DURING ANTIDIUREsis [modified from Ullrich, Kramer, and Boylan (6)]. the collecting tubular concentration of urea, thereby creating a concentration gradient for urea across the tubular wall. Since the wall is permeable to urea, particularly in the presence of vasopressin, urea leaves the collecting tubule and flows along this gradient through the medullary interstitium into the descending limb of Henle's loop, where micropuncture studies have documented its appearance (25). Lassiter and associates have obtained evidence which suggests that the descending limb of Henle's loop is relatively permeable, whereas the ascending limb is relatively impermeable to urea (25). If we assume that this difference in urea permeability is relatively greater than any difference in water permeability between the limbs, urea in the ascending limb can exert an osmotic effect across the walls of the ascending limb to detain water within the limb while sodium is transported out of the limb. This detaining effect of urea on water within the ascending limb would allow a higher concentration of sodium to be achieved in the medullary interstitium, thereby increasing the driving force for water reabsorption from the collecting tubular fluid. Thus the ultimate effect of urea acting osmotically across the wall of the ascending limb of Henle's loop would be an increase in the final concentration of the urine. Possibly reflecting such an action of urea is the recent observation of Manitius, Pigeon, and Epstein that the calculated concentration of sodium and of potassium in the medullary interstitial fluid is higher in protein-fed than in protein-deprived dogs (26). Substantiation of this hypothesis must await further experimental observations.

\section{Summary}

Using an in vitro technique of collecting tubular perfusion, we studied the effect of vasopressin on the movement of urea $\mathrm{C}^{14}$ and sucrose $\mathrm{C}^{14}$ out of the rat collecting tubule. Papillae exposed to vasopressin in vivo contained more water and more urea $\mathrm{C}^{14}$ after in vitro perfusion than did paired controls. Similar differences were not obtained when saline without vasopressin, sucrose $\mathrm{C}^{14}$ instead of urea $\mathrm{C}^{14}$, or hypertonic instead of isotonic perfusate was used. We concluded that urea moves more readily across the collecting tubular wall in the presence of vasopressin and that its movement is attributable in part to an increased 
permeability of the collecting tubular wall to urea and in part to solvent drag from the accompanying movement of water. A postulate is advanced to account for the ability of urea to enhance water reabsorption in the kidney of the rat and perhaps in other mammals.

\section{Acknowledgments}

We are grateful to Mrs. Dorothea Cooney for her technical help and to Byron William Brown, Jr., for his assistance with the statistical evaluation of the data.

\section{References}

1. Wirz, H. The production of hypertonic urine by the mammalian kidney in The Kidney, Ciba Foundation Symposium. Boston, Little, Brown, 1954, p. 38.

2. Berliner, R. W., N. G. Levinsky, D. G. Davidson, and M. Eden. Dilution and concentration of the urine and the action of antidiuretic hormone. Amer. J. Med. 1958, 24, 730.

3. Gottschalk, C. W. Micropuncture studies of tubular function in the mammalian kidney. Physiologist 1961, 4, 35.

4. Hilger, H. H., J. D. Klümper, and K. J. Ullrich. Wasserrückresorption und Ionentransport durch die Sammelrohrzellen der Säugetierniere (mikroanalytische Untersuchungen). Pflügers Arch. ges. Physiol. 1958, 267, 218.

5. Ullrich, K. J., F. O. Drenckhahn, and K. H. Jarausch. Untersuchungen zum Problem der Harnkonzentrierung und -verdünnung. Uber das osmotische Verhalten von Nierenzellen und die begleitende Elektrolytanhäufung im Nierengewebe bei Verschiedenen Diuresezuständen. Pflügers Arch. ges. Physiol. 1955, 261, 62.

6. Ullrich, K. J., K. Kramer, and J. W. Boylan. Present knowledge of the counter-current system in the mammalian kidney in Heart, Kidney, and Electrolytes, C. K. Friedberg, Ed. New York, Grune \& Stratton, 1962, p. 1.

7. Altman, P. L., and D. S. Dittmer. Blood and Other Body Fluids. Washington, D. C., Fed. Amer. Soc. exp. Biol., 1961, pp. 370-374.

8. Levinsky, N. G., and R. W. Berliner. The role of urea in the urine concentrating mechanism. J. clin. Invest. 1959, 38, 741.

9. Crawford, J. D., A. P. Doyle, and J. H. Probst. Service of urea in renal water conservation. Amer. J. Physiol. 1959, 196, 545.

10. Gamble, J. L., C. F. McKhann, A. M. Butler, and E. Tuthill. An economy of water in renal function referable to urea. Amer. J. Physiol. 1934, 109, 139.
11. Astarabadi, T., and E. T. Bell. Spontaneous hydronephrosis in albino rats. Nature (Lond.) 1962, 195, 392.

12. Thorn, N. A. A densimetric method for assay of small amounts of antidiuretic hormone. J. exp. Med. 1957, 105, 585.

13. Krebs, H. A. Body size and tissue respiration. Biochim. biophys. Acta (Amst.) 1950, 4, 249.

14. Ginetzinsky, A. G. Role of hyaluronidase in the reabsorption of water in renal tubules: the mechanism of action of the antidiuretic hormone. $\mathrm{Na}$ ture (Lond.) 1958, 182, 1218.

15. Stolarczyk, J., and A. Manitius. Morphology of the collecting tubules in diuretic and antidiuretic rats. Proc. Soc. exp. Biol. (N. Y.) 1962, 110, 849.

16. Smith, H. The Kidney: Structure and Function in Health and Disease. New York, Oxford University Press, 1951, p. 102.

17. Maffly, R. H., R. M. Hays, E. Lamdin, and A. Leaf. The effect of neurohypophyseal hormones on the permeability of the toad bladder to urea. J. clin. Invest. 1960, 39, 630.

18. Leaf, A., and R. M. Hays. Permeability of the isolated toad bladder to solutes and its modification by vasopressin. J. gen. Physiol. 1962, 45, 921.

19. Schmidt-Nielsen, B. Urea excretion in mammals. Physiol. Rev. 1958, 38, 139.

20. Jaenike, J. R. The influence of vasopressin on the permeability of the mammalian collecting duct to urea. J. clin. Invest. 1961, 40, 144.

21. Bray, G. A., and A. S. Preston. Effect of urea on urine concentration in the rat. $\mathrm{J}$. clin. Invest. 1961, 40, 1952.

22. Drescher, A. N., H. L. Barnett, and V. Troupkou. Water balance in infants during water deprivation. Amer. J. Dis. Child. 1962, 104, 366.

23. Ullrich, K. J., B. Schmidt-Nielsen, R. O’Dell, G. Pehling, C. W. Gottschalk, W. E. Lassiter, and M. Mylle. Micropuncture study of composition of proximal and distal tubular fluid in rat kidney. Amer. J. Physiol. 1963, 204, 527.

24. Wirz, H. The location of antidiuretic action in the mammalian kidney in The Neurohypophysis, $\mathrm{H}$. Heller, Ed. New York, Academic Press, 1957, p. 157.

25. Lassiter, W. E., C. W. Gottschalk, and M. Mylle. Micropuncture study of net transtubular movement of water and urea in nondiuretic mammalian kidney. Amer. J. Physiol. 1961, 200, 1139.

26. Manitius, A., G. Pigeon, and F. H. Epstein. Mechanism by which dietary protein enhances renal concentrating ability. Amer. J. Physiol. 1963, 205, 101. 